\title{
Claudio Ptolomeo y el lenguaje. Un comentario a Iudic., 2-6
}

\author{
Pedro Redondo Reyes \\ Universidad de Murcia \\ predondo@um.es \\ ORCID iD: http://orcid.org/0000-0002-5426-3848
}

\section{Claudius Ptolemy on language. A Commentary on Iudic., 2-6}

\begin{abstract}
El tratado Sobre el juicio y el principio rector de Claudio Ptolomeo, consagrado al estudio de los criterios de conocimiento, constituye el marco epistemológico de la práctica científica de este autor. Para Ptolomeo el lenguaje tiene un papel destacado como vehículo de transmisión del juicio, y en el tratado se estudia su relación con la parte racional del ser humano, así como su origen y propiedades filosóficas.
\end{abstract}

Palabras clave: Claudio Ptolomeo; criterio; lenguaje; filosofía helenístico-imperial.
Ptolemy's treatise On the Criterion and Commanding Faculty, dedicated to the study of the criteria of true, constitutes the epistemological frame of the scientific practice of this author. According to Ptolemy, language plays an important role as vehicle of transmission of the judgment, and in Ptolemy's treatise its relationship with the rational part of the human being is set out, as well as its origin and philosophical properties.

Key words: Claudius Ptolemy; criterion; language; Hellenistic philosophy.

Cómo citar este artículo / Citation: Redondo Reyes, Pedro 2017: «Claudio Ptolomeo y el lenguaje. Un comentario a Iudic., 2-6», Emerita 85 (2), pp. 289-311.

El opúsculo Sobre el juicio y el principio rector (en adelante, Iudic.) ${ }^{1}$, atribuido a Claudio Ptolomeo (ca. 100-170 d. C.), pertenece a una larga tradición filosófica relativa a la posibilidad de conocimiento, determinado por el lla-

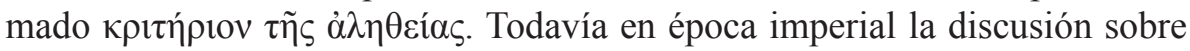

${ }^{1}$ Edición de Lammert 1961, pp. 3-25. Los principales estudios generales son Boll 1894, p. 77 ss., Long 1989 y Schiefsky 2014. Su atribución fue discutida, aunque su adscripción a Ptolomeo tiende a imponerse, cf. Tolsa 2016, p. 465 n.2.

Copyright: (C) 2017 CSIC. Este es un artículo de acceso abierto distribuido bajo los términos de la licencia de uso y distribución Creative Commons Attribution (CC-by) España 3.0. 
la naturaleza y los límites del criterio de verdad era un problema filosófico, heredado de la filosofía de época helenística².

El origen del término крıт́́pıov se halla en el ámbito judicial y había sido utilizado ya por Platón a partir de este contexto ${ }^{3}$. Ptolomeo, siguiendo la recomendación aristotélica de usar comparaciones en la argumentación ${ }^{4}$, dispone todas las instancias que intervienen en el conocimiento a la manera de un tribunal de justicia: objeto del juicio (

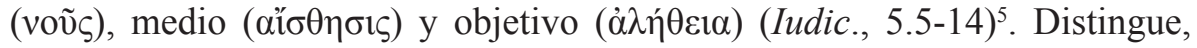
además, dos facultades en el ser humano relativas al instrumento y al medio:

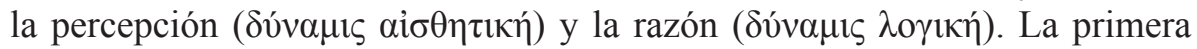
contiene los sentidos y la $\varphi \alpha v \tau \alpha \sigma i ́ \alpha$, «impresión y transmisión hasta el intelecto». Por su parte, a la facultad racional, específica de los humanos, perte-

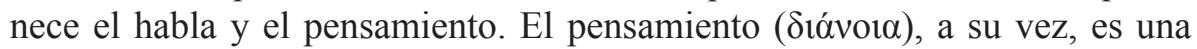

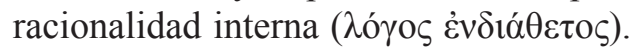

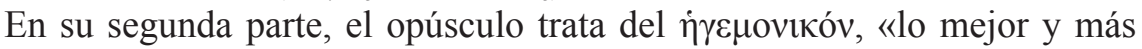
valioso» que en este sentido se localiza en el cerebro (15, 22.1-6), como Platón; pero también se puede hablar de él en el sentido de funciones anímicas y entonces debe entenderse localizado en todas las partes del cuerpo, sobre todo en el corazón, como los estoicos ${ }^{6}$. En general, el aparato conceptual ptolemaico no entraña la exactitud de otras escuelas filosóficas. La búsqueda de fuentes del tratado arroja por ello conclusiones diversas: desde un predominio de la orientación peripatética hasta la Estoa media, a lo que hay que añadir fuentes epicúreas y escépticas?

2 Striker 1996a, p. 23, Lucci 1980, pp. 29-32.

3 Striker 1996a, p. 24 ss., Schiefsky 2014, p. 308.

${ }^{4}$ Arist., Top. 156b25-27, cf. Tolsa 2013, p. 124.

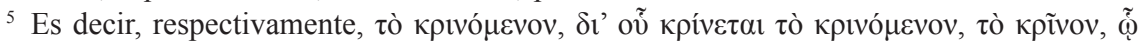

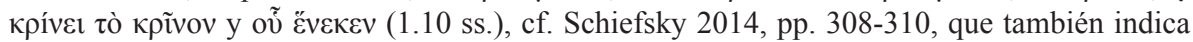
la similitud con las prácticas legales del Egipto grecorromano. Tolsa 2013, pp. 125, 134 y 2016, p. 468 señala el precedente de la comparación en Filón de Alejandría (Congr. 143). El esquema ptolemaico es un eco del que presenta Sexto Empírico ( $H$. II 14 ss., $M$. VII 36).

${ }^{6}$ Boll 1894, p. 92, cf. Manuli 1981. Para Long 1989, pp. 170-171 esto es una muestra de lo que él llama optimum agreement que es la marca de Iudic. en cuanto a la incorporación de material de distinta procedencia.

7 Lammert 1917, p. 257 (Posidonio); Boll 1894, p. 77 ss.; Manuli 1981, pp. 64-66 (relación estrecha con el platónico Albino); Long 1989, p. 163 y n.34, 174 ss., 177 n.42; Tarrant 1985, p. 110; Tolsa 2013, p. 123, 2016, p. 471. Long sostiene la presencia de Antíoco de Ascalón en la doxografía de Sexto sobre la cuestión (y por tanto, por su similitud, en Pto- 
Los mejores acercamientos a Iudic. son los de Long (1989), Tolsa (2013) y Schiefsky $(2014)^{8}$, pero se trata de panorámicas generales sobre el problema del criterio. Nuestro objetivo aquí es centrarnos tan sólo en la perspectiva que sobre el lenguaje toma Ptolomeo, cuestión no baladí en el esquema argumental del opúsculo. Ello es índice de cómo en época imperial las relaciones entre lenguaje y filosofía seguían estando presentes desde su discusión en el Crátilo platónico y los sofistas. Ptolomeo debe moverse en un contexto en el que las distintas escuelas filosóficas ya han desarrollado sus propios términos técnicos. Su propio acercamiento a la cuestión en Iudic. pasa por la idea del lenguaje como instrumento de la razón emisora,

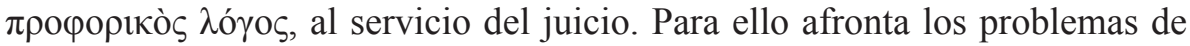
la relación entre pensamiento y habla, los elementos constitutivos del lenguaje, la terminología apropiada para el juicio y el origen del lenguaje. Tales apreciaciones están articuladas, como es normal en este autor, en un estilo complicado y apuntan concretamente, quizás a través de fuentes intermedias (como Antíoco o Aristón) ${ }^{9}$, a Aristóteles y el epicureísmo.

Los excursus sobre el lenguaje ocupan secciones entre los capítulos 2-6 de la edición de Lammert, cuyo texto y paginación seguimos aquí, y se ubican tras la presentación de los elementos del criterio y la distinción entre $\lambda$ ó $\gamma o \varsigma$

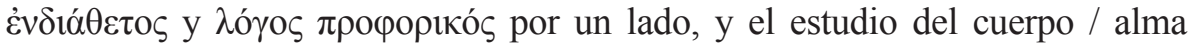

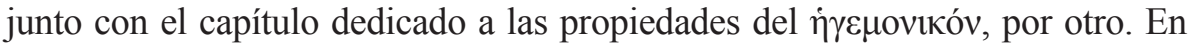
lo que sigue, hemos dividido el texto en cuestión en unidades temáticas, que tienen naturaleza de pequeños incisos en el discurso epistemológico del tratado.

\section{Los elementos del lenguaje: Iudic. 2.5 (6.2-11 Lamm.)}

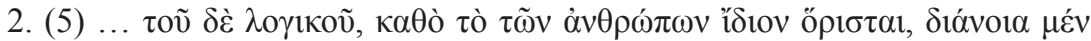

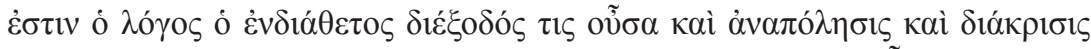

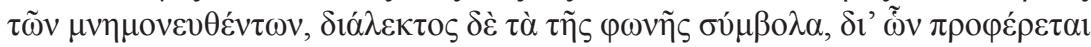

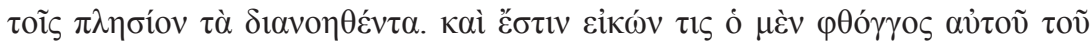

lomeo). Tolsa rastrea la influencia sobre el opúsculo ptolemaico de uno de los discípulos de Antíoco, Aristón de Alejandría.

${ }^{8}$ Long 1989 y Schiefsky 2014 son presentaciones generales del opúsculo ptolemaico y no se detienen en la cuestión del lenguaje; por su parte, Tolsa 2013 se centra, siguiendo a Long, sólo en la influencia epicúrea sobre la misma. Verlinsky 2005 es una comparación con Epicuro de Iudic. 4.2-6.

${ }^{9}$ Long 1989, p. 163; Tolsa 2013. 


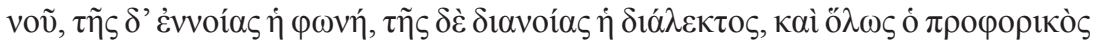

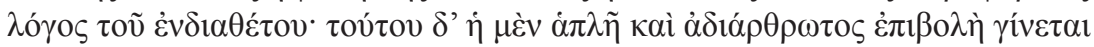

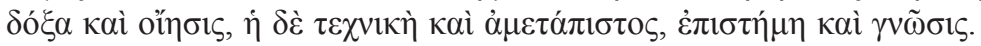

En 2.2, Ptolomeo había establecido que de las cinco instancias en el acto de juzgar, la verdad y el intelecto (voũ $\varsigma$ ) serían los límites. Percepción y razón son intermedios. Se plantean por tanto dos facultades, la facultad de la per-

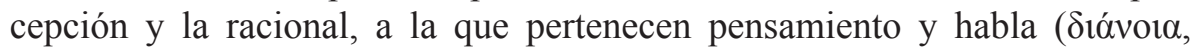
$\delta i \alpha ́ \lambda \varepsilon \kappa \tau O \varsigma)$. Los animales irracionales poseen sólo la primera de las facultades, y esta reserva de la facultad racional para el hombre es compartida por Ptolomeo con la tradición aristotélica ${ }^{10}$, con la consecuencia de que el lenguaje significativo (o articulado) es privativo de éste ${ }^{11}$. En todo caso, Iudic. separa dos esferas: la sensitiva y la racional ${ }^{12}$.

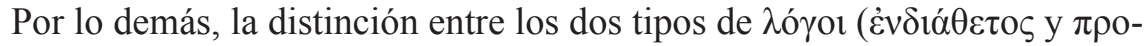

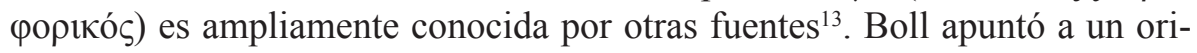
gen estoico, pero su origen exacto no es localizable por más que apunte a Platón ${ }^{14}$ : según Teón de Esmirna (72.24 ss. H.), los aristotélicos vinculan el

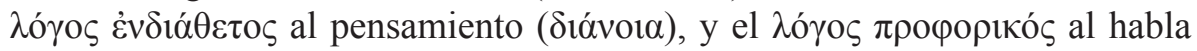
$(\delta i \alpha ́ \lambda \varepsilon \kappa \tau O \zeta)^{15}$. Para Ptolomeo, la relación entre ambos es la de «imagen»,

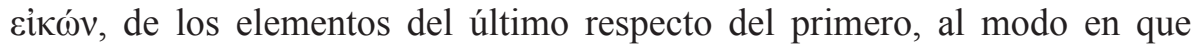
Aristóteles en De interpretatione hace a la $\varphi \omega v \eta ́$ seguidora de la $\delta$ ióvot ${ }^{16}$. Según Ptolomeo, el hablar es símbolo ${ }^{17}$ de la voz, lo que lleva al mismo tex-

${ }_{10}$ Arist., de An. 414b18, por ejemplo, aunque con terminología diferente en autores estoicos, pitagóricos o neoplatónicos.

11 Cf. Arist., HA 535a-b, de An. 420b29-30, Pol. 1456 b24.

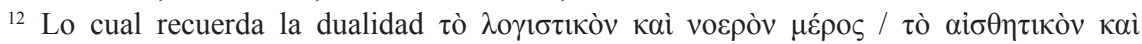

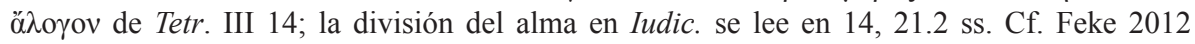
para su discusión.

13 Theo Sm., 72.24-73.2, Porph., in Cat. 64.28 ss. (cf. Ptol., Iudic. 15, p.22.8), S. E., H. I 65 ss., Nemes., Nat.Hom. 14, etc.

${ }^{14}$ Cf. Pl., Phlb. 38e, Tht. 206d. Véase Boll 1894, p. 85, Chiesa 1992, p. 23 (con otras fuentes), quien postula que la distinción fue utilizada por los estoicos en su debate con los académicos, y Mansfeld 2005, pp. 373, 378 ss., n. 48 y 57.

15 Schiefsky 2014, p. 314 encuentra un eco de la identificación de $\lambda$ ó $\gamma$ os con un tipo de conversación interna en P1., Sph. 263e, Tht. 189e-190a.

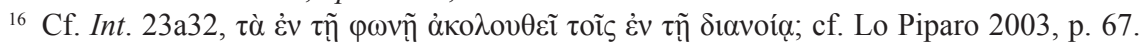

17 Sobre su significado e interpretación en Aristóteles, cf. Chiesa 1986, p. 205 ss. Para Chiesa el carácter simbólico conlleva que la expresión vocal significa sólo a condición de reenviar a un contenido psíquico determinado (p. 210); para Lo Piparo 2003, pp. 66-67, se 


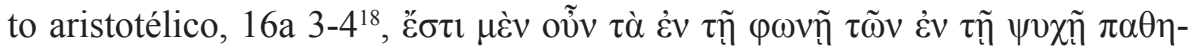

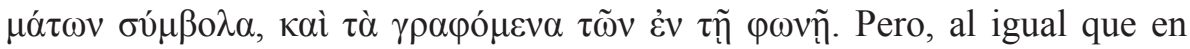
Aristóteles, también el texto ptolemaico es poco claro, pues la conexión entre habla y voz no parece guardar prima facie una relación simbólica; además,

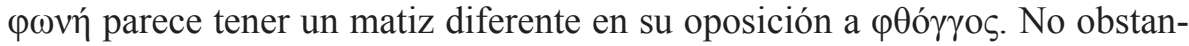

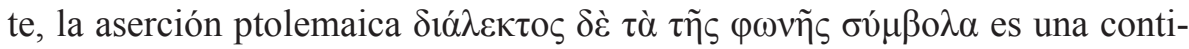

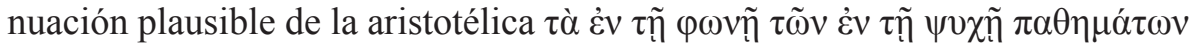
$\sigma 0 ́ \mu \beta o \lambda \alpha$. Por lo demás, que el habla «transmita» a los demás lo pensado es otro locus communis, cf. Sch. D. T. 181.37.

A continuación, Ptolomeo articula la conocida tríada sonido-voz-lenguaje, que tiene su antecedente más relevante en Aristóteles así como en el $\Pi \varepsilon \rho i ̀ ~ \varphi \omega v \tilde{\eta} \varsigma$ $\tau \dot{\chi} \chi v \eta$ de Diógenes de Babilonia ${ }^{19}$, tal y como es transmitido por Diógenes Laercio (VII $55=S V F$ III 20), que a juicio de Ax habría recibido el influjo peripatético ${ }^{20}$. Aristóteles ${ }^{21}$ distingue en pasajes como HA 535a27 ss. o GA 786b24 entre

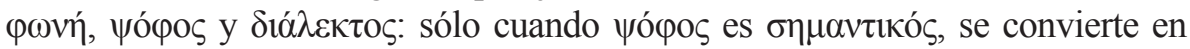
$\varphi \omega v \eta ́$ (de An. 420b32); también lo es cuando es animado (ibíd., b5)22. Ax 2000a ha estudiado profusamente las relaciones y el significado de estos términos en las fuentes antiguas; baste aquí mencionar que Aristóteles se detiene principalmente en esta distinción al hilo de los sonidos animales (p. ej., HA 488a31 ss.).

La relación entre Aristóteles y la propia distinción de Diógenes de Babilonia

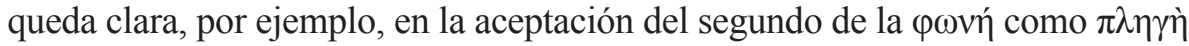

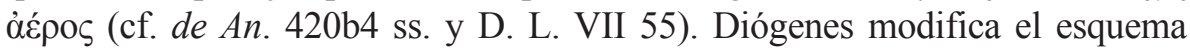
aristotélico proponiendo, en lugar del mero yópos como punto de partida, una $\varphi \omega v \eta ́$ que puede ser simple $\tilde{\eta} \chi 0 \varsigma$, mientras que si es articulada es la propia del ser humano. Este tipo de $\varphi \omega v \eta ́$ ya es $\lambda \varepsilon_{\varepsilon} \xi 1 \zeta$ según Diógenes, a la que define

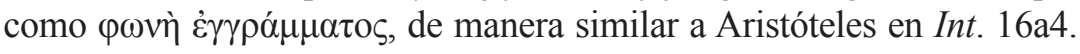

trata de una relación entre la articulación vocal y las operaciones lógico-cognitivas: «simbolo è il termine teorico che indica la genesi, contemporanea e complementare, dell'articolazione vocale (di cui solo gli animali umani sono capaci) e dell'insieme delle operazioni logico-cognitive che, anch'esse, appartengono solo all'animale umano».

${ }_{18}$ Para el pasaje aristotélico y sus ambigüedades, cf. Ackrill 1963, p. 113 y Chiesa 1986, pp. 203-204.

${ }^{19}$ Huby y Neal 1989, p. 221; Schenkeveld 1990, p. 104 para las observaciones contra Frede 1978 de la dependencia de la gramática estoica de Teofrasto y no de Aristóteles.

${ }^{20}$ Para esto, cf. Ax 2000a y Arbo 2006, p. 220. Para la diferencia entre los estoicos y Aristóteles respecto a $\lambda \dot{\varepsilon} \xi 1 \zeta$, cf. Lo Piparo 1999, p. 122 y Ax 2000b, p. 81 ss.

${ }^{21}$ Zirin 1980, p. 335 ss., Ax 2000a, p. 23.

${ }^{22}$ Ax 2000a, p. 27. 


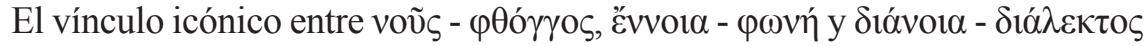
establece una tríada en los elementos del lenguaje que difiere de los vistos en Aristóteles y Diógenes ${ }^{23}$. Ptolomeo coincide con Aristóteles en la situación intermedia de $\varphi \omega v \eta ́$, mientras que Diógenes la colocaba como mero aire gol-

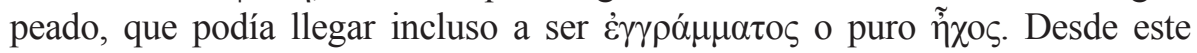
punto de vista es similar al aristotélico $\psi$ ó cidad significativa del término $\varphi \omega v \eta$. En Harm. I 4, Ptolomeo denomina

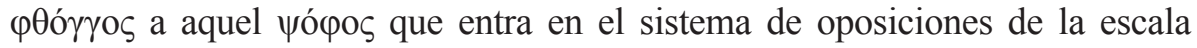
musical; pero en otras fuentes peripatéticas, $\varphi \theta$ ó $\gamma \gamma \circ \varsigma$ es «nota» como algo primario e indivisible (Adrasto, ap. Theo Sm. 49.10-11 y 18-19, al modo en que también para Diógenes la $\varphi \omega v \eta ́$ es el comienzo ${ }^{24}$ ). De este modo, Ptolomeo tenía a su disposición una tradición peripatética que hacía del $\varphi \theta$ ó $\gamma$ os el elemento primario ${ }^{25}$, además del propio significado que ya tenía de mero sonido (cf. Pl., Phlb. 18c 1). Y su vinculación a voũ lo define como cualidad huma$\mathrm{na}^{26}$, siendo ambos límites tanto de la intelección como de la comunicación. Por su parte, $\varphi \omega v \eta ́$ también es «voz» en Harm. (I 4, 10.26), la voz humana ${ }^{27}$.

${ }^{23}$ Recordemos cómo Aristóteles formula la tríada y su gradación referida a los animales, cf. $H A$ 488a31, 535a27. En la parte dedicada al sonido en De anima establece una gradación similar

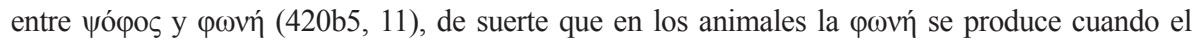
sonido es emitido en una parte determinada del cuerpo (cf. Lo Piparo 2003, p. 155). Efectivamente, la vinculación entre el modelo aristotélico y el ptolemaico de Iudic. 2 pasaría por la capacidad física del ser vivo de emitir sonido (que sería ya $\varphi \omega v \eta ́$ si se asocia a una representación,

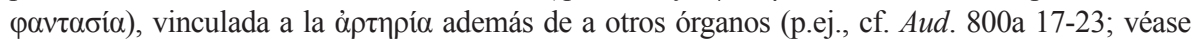
Lo Piparo 2003, p. 156): cf. Arist., De an. 420b33-421a1, HA 535b14 y Ptol., Harm. I 3 p.9.4-6 D. Las causas de la agudeza o gravedad en las voces son diferentes en Aristóteles y Ptolomeo: el primero las relaciona con la temperatura del aire (GA 788a, Pr. XI 13), mientras que el segundo las condiciona a las longitudes (Harm. I 3; cf. Aud. 800 a-b). Cf. además Ax 2000a, p. 23.

${ }^{24}$ Lo importante para Harm. I 4 respecto a $\varphi \theta$ ó $\gamma$ os es que se trata de un sonido delimitado

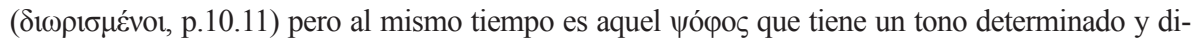

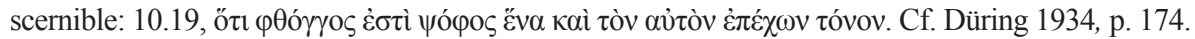

${ }^{25}$ Se trata del conocido paralelismo entre gramática y música, presente en multitud de fuentes (Pl., Crat. 424c, Phlb. 17b, Arist., Metaph. 1053a12 ss., etc.), que incluso puede incidir en otros elementos, como la comparación de $\varphi \theta$ óyos con los elementos primarios en geometría y aritmética.

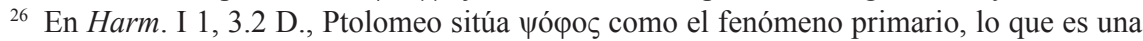
reformulación de la definición de $\varphi \omega v \eta ́$ de Diógenes así como un locus communis en la tradición musical (cf. Ps. Plu., de Mus. 1131d2-3); en el peripatético Aud. (800a1-3) la percusión es la causa de $\varphi \omega v \alpha i ́$ y $\psi$ ópor (la otra explicación peripatética es la velocidad de propagación del aire, cf. $\operatorname{Pr}$. XI 6). Cf. Bobo de la Peña 2009, p. 551 y n.9, 11.

${ }^{27}$ Bobo de la Peña 2009, p. 552. 
Ptolomeo comienza su gradación con el mero sonido, ahora భó $\varphi$ os (imagen del voũ $)$, seguido de $\varphi \omega v \eta ́$ como imagen de la Ěvvora. Así, también en

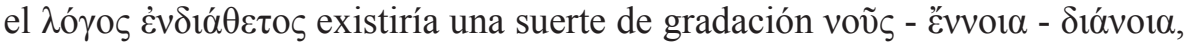

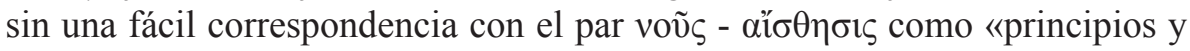
elementos» $(4,7.7)^{28}$; por su parte, había establecido que la $\delta$ ióvoı $\alpha$ era una de las dos partes de la facultad racional junto al habla $(\delta \dot{\alpha} \lambda \varepsilon \kappa \tau o \varsigma)^{29}$, y de la

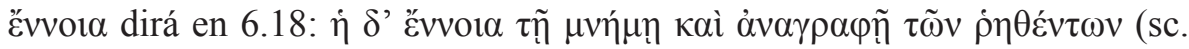

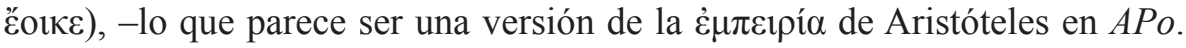
100a 4-b5 $5^{30}$, permitiendo que el contenido de las impresiones sensibles pueda ser transmitido. Otra obra ptolemaica con doctrina gnoseológica, Harmonica, contiene correspondencias casi verbatim ${ }^{31}$. Si en Iudic. la tríada voṽ -

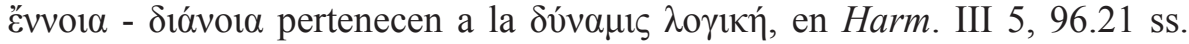

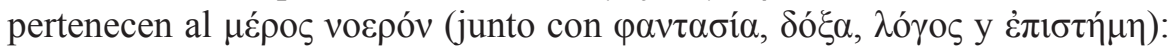

\begin{tabular}{|c|c|c|}
\hline & Harm. III 5 & Iudic. 2.4 ss. \\
\hline$\varphi \alpha \nu \tau \alpha \sigma i \alpha$ & 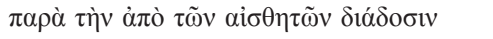 & 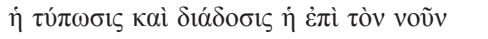 \\
\hline voñ & 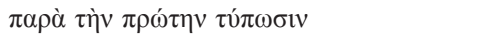 & 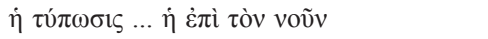 \\
\hline Ëvvol $\alpha$ & 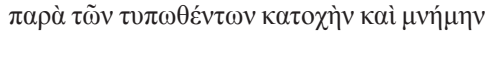 & 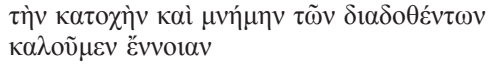 \\
\hline 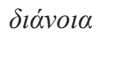 & 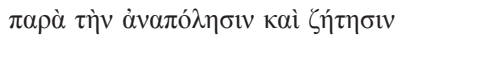 & 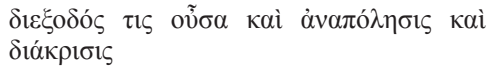 \\
\hline$\delta \dot{\xi} \xi \alpha$ & 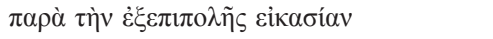 & 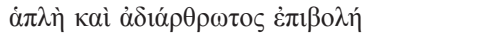 \\
\hline$\lambda o ́ \gamma o \varsigma$ & 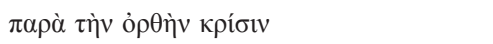 & 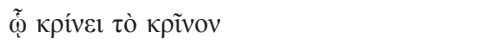 \\
\hline$\dot{\varepsilon} \pi \imath \sigma \tau \dot{\eta} \mu \eta$ & 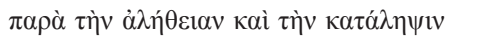 & 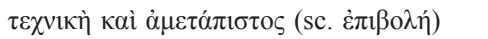 \\
\hline
\end{tabular}

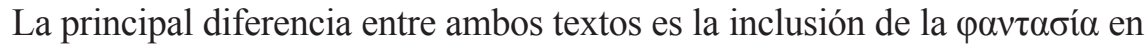

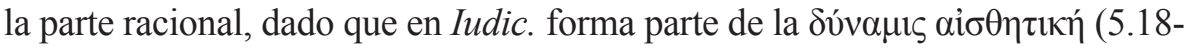

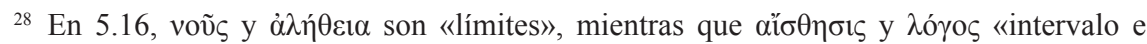
intermedios»; cf. Huby y Neal 1989, p. 220 y Schiefsky 2014, p. 313.

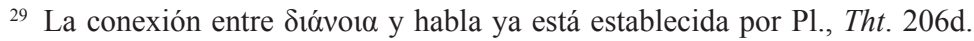

${ }^{30}$ Cf. para esto Schiefsky 2014, p. 315, que señala que, aunque Ptolomeo coloca la Ěvvora en la parte perceptiva, su contenido se expresa mediante el $\lambda$ ó $\gamma o \varsigma$.

${ }^{31}$ Estos paralelismos inciden en la idea de que Iudic. tiene un carácter propedéutico para la práctica científica de diferentes disciplinas, al proveer de un armazón conceptual para cualquier investigación (Harm. III 5 no adquiere su pleno sentido sin Iudic. 2.4 ss.). Los escolios a Harm. han supuesto que esta obra fue la última escrita por Ptolomeo, cf. Boll 1894, p. 65 y Long 1989, p. 169. 


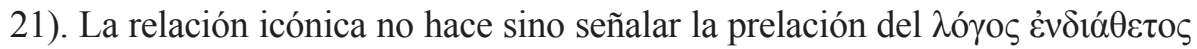
en el acto de juzgar. Más adelante Ptolomeo dirá que el lenguaje es «instrumento» (6.3), y consecuentemente su claridad y precisión serán reflejo de la claridad en el resultado del juicio. Si en Iudic. la gradación da cuenta de planos lingüísticos sucesivos, en Harm. ocurre lo mismo con los elementos integrantes del sistema musical: la idea subyacente es que el «aparato» epistemológico (de procedencia aristotélico-estoica) que acepta de un modo laxo puede organizar y clasificar cualquier objeto estudiado por una disciplina.

Por lo demás, estamos ante términos técnicos de la koiné filosófica helenís-

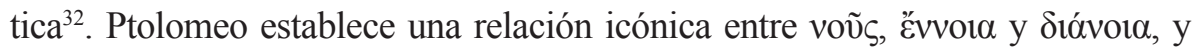

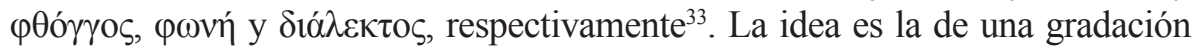
que establece dos planos, el interno y el lingüístico: Ěvvoı $\alpha$ funciona de manera intermedia como recuerdo y recapitulación de las impresiones recibidas, que serán expresadas mediante el lenguaje: en ello no sólo sigue a Aristóteles (Int.

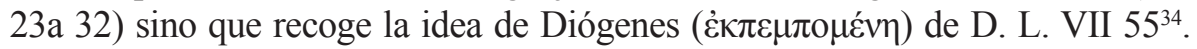
Por otro lado, la aportación ptolemaica de la «imagen» de lo hablado respecto a lo pensado funciona como introducción a su idea (cf. infra, 4.3 ss.) de que en el origen del lenguaje hay un componente natural, físico, seguido de otro convencional una vez se desarrolla la sociedad ${ }^{35}$. Ptolomeo es crítico con una visión únicamente convencionalista (cf. 5.4), que conduce a una dialéctica perturbadora de la correcta kpíoic. La idea subyacente es que la mera concepción convencionalista y erística (como le parecería la de los estoicos) del lenguaje no permitía establecer un puente simple entre el entendimiento y la realidad: como dirá

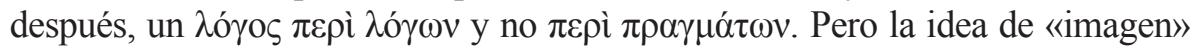
entre lo hablado y lo pensado contiene más ecos: દi் ptolemaico para expresar la inmediatez que Epicuro -cuyas ideas sobre el origen

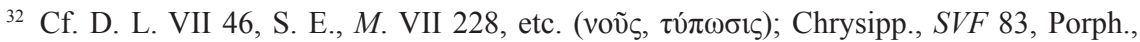
in Harm. 14.3, S. E., M. VII 223-224, Aristid. Quint. II 7, 65.22 ss. W.-I. (Ëvvola). Arístides Quintiliano ofrece una interesante concepción de $\varepsilon^{\prime} v o 1 \alpha$, que vincula a $\lambda \dot{\varepsilon} \xi 1 \zeta$, de manera semejante a como Ptolomeo lo hace con $\varphi \omega v \eta ́$, el equivalente a la $\lambda \varepsilon^{\xi} \xi 1 \varsigma$ de Diógenes de Babi-

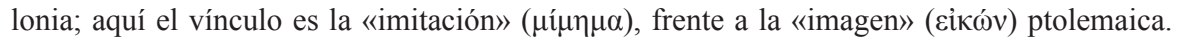

${ }^{33}$ Schiefsky 2014, p. 315.

${ }^{34}$ Otros loci con ideas muy próximas para esta relación los recoge Mansfeld 200 (cf. p. ej. Ph., Det. 40)

35 Ya Platón (Tht. 208c; cf. Chiesa 1993, p. 26 y Mansfeld 2005, p. 397 n.139) llama

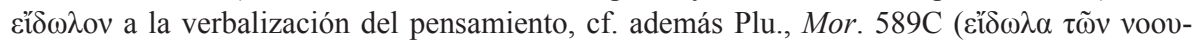

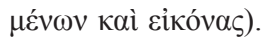


del lenguaje están, como veremos, bajo las de Ptolomeo en Iudic. 4.3 ss.- esta-

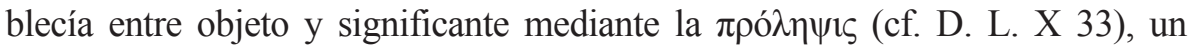
concepto que asegura la igualdad en la «preconcepción» de las cosas a todos los hombres ${ }^{36}$. Y, de otro lado, funciona como la traducción ptolemaica del $\sigma 0 ́ \mu \beta o \lambda o v$ de Aristóteles y su tratamiento y extensión en sus comentaristas ${ }^{37}$.

En cuanto a la noción ptolemaica de $\delta i \alpha ́ \lambda \varepsilon \kappa \tau o \varsigma$, mientras que Diógenes la

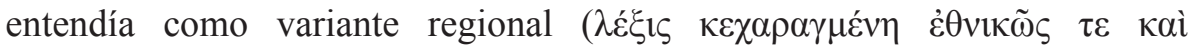
'E $\lambda \lambda \eta v i \kappa \tilde{\omega} \varsigma)$, Aristóteles la entiende como «lenguaje», voz articulada y significativa propia del hombre ${ }^{38}$ según se desprende de $H A 535 \mathrm{~b} 1$ ss.; ésta es la idea que aparece en Iudic. La definición aristotélica es la de $H A$ 535a30

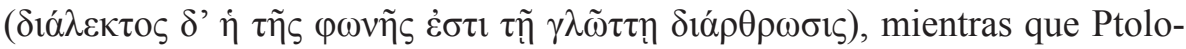
meo insiste en el término $\sigma 0 ́ \mu \beta 0 \lambda$ ov siguiendo a De interpretatione ${ }^{39}$. En otros pasajes peripatéticos también se hace seguir a $\delta \dot{\alpha} \lambda \varepsilon \kappa \kappa \tau o \varsigma$ a partir de $\varphi \omega v \eta ́$, como en $\operatorname{Pr}$. 898b30, o se afirman las letras como $\pi \alpha \theta \dot{\mu} \mu \alpha \tau \alpha$ de la $\varphi \omega v \eta ́$, de suerte que Ptolomeo no haría sino completar el último nivel:

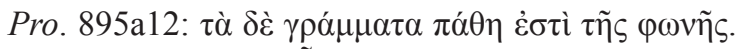

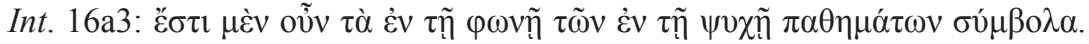

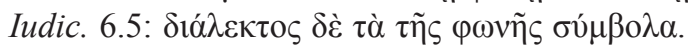

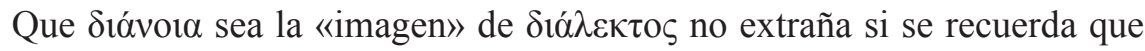

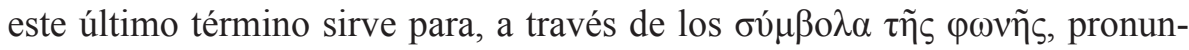

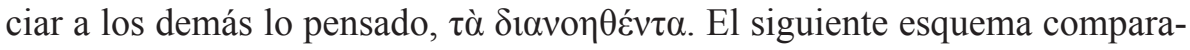
tivo recoge las diferencias entre Ptolomeo y sus precursores:

\begin{tabular}{|c|c|c|c|}
\hline Aristóteles & Diógenes Bab. & Ptol., Iudic. 2 & Ptol., Harm. I 3 \\
\hline 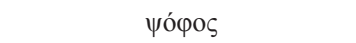 & $\varphi \omega v \eta ́$ & $\varphi \theta 0 ́ \gamma \gamma \circ \varsigma$ & 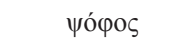 \\
\hline$\varphi \omega v \eta ́$ & $\lambda \dot{\varepsilon} \xi 1 \zeta$ & $\varphi \omega v \eta ́$ & $\varphi \theta$ ó $\gamma \gamma о \varsigma$ \\
\hline 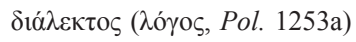 & 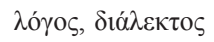 & 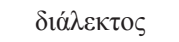 & $\varphi \omega v \eta ́ ~(10.26)$ \\
\hline
\end{tabular}

${ }^{36}$ Cf. Long 1971, 120-121.

${ }^{37}$ Cf. Ammon., in Int. 23.13-14, Boll 1894, p. 85.

${ }^{38}$ HA 536a32, pero cf. Ax 2000b, p. 90 («artikulierter Stimmlaut von Mensch/Tier»).

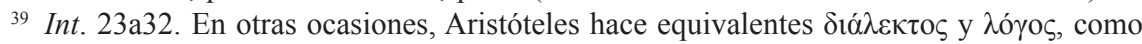
en Pol. $1253 \mathrm{a} 10$ ss., cf. Ax 2000a, p. 31, o en GA 786b21, con un sentido más general que el

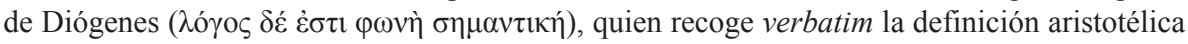

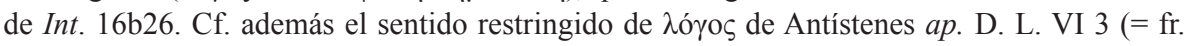
45 Caizzi) y la crítica aristotélica en Metaph. $1024 b 32$. 


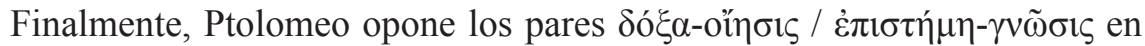
un esquema tradicional en la filosofía griega ${ }^{40}$. En la versión ptolemaica per-

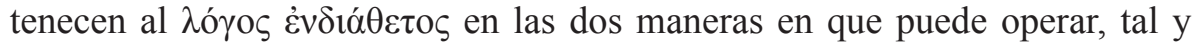
como especifica más adelante (12, 18.11-14 y 14, 21.8 ss.). La distinción ya está en Platón ( $R .479 \mathrm{~d}$ ss., 509d-511e), y Long ya señala el uso por los escritores de época imperial de غ̇ंı

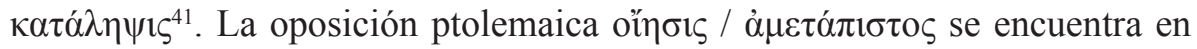
Arr., Epict. III 14.8; pero para Ptolomeo se trata de una formulación general de la oposición entre un conocimiento indubitable provisto por las ciencias, que operan sobre un dominio físico cambiante de un modo limitado ${ }^{42}$, sobre lo que vuelve en Alm., I 1 (I 6.11-21 H.) al calificar de sik $\alpha \sigma i ́ \alpha$, «conjetura», a la teología y la física por sus características no perceptibles y cambiantes respectivamente. En cambio las matemáticas proveen de un conocimiento

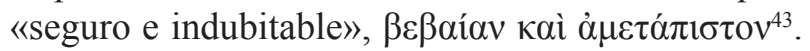

2. Términos usuales y origen del lenguaje: Iudic. 4.2-6 (7.12-8.12 Lamm.)

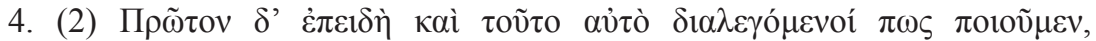

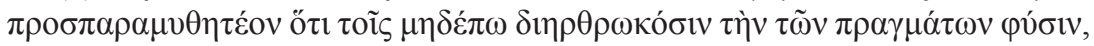

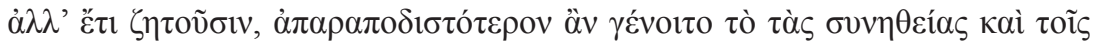

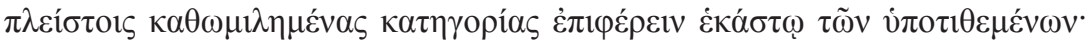

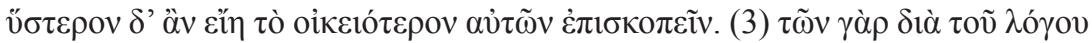

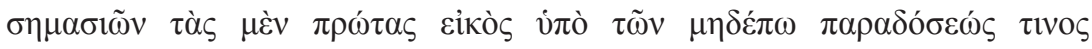

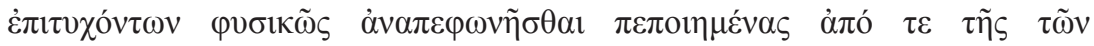

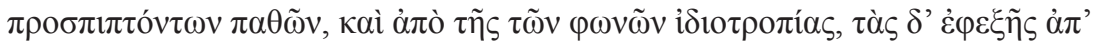

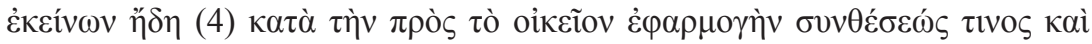

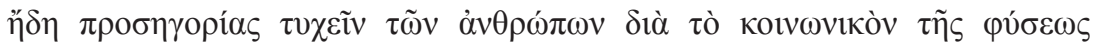

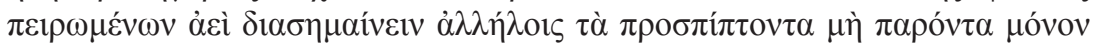

40 Long 1989, p. 155.

${ }^{41}$ Long 1989, p. 221.

42 Schiefsky 2014, pp. 306, 307 n. 24.

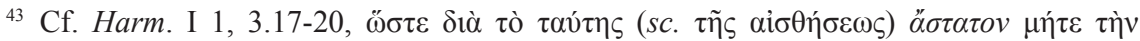

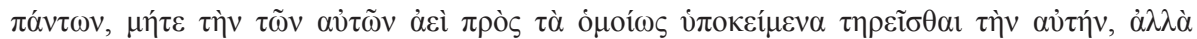

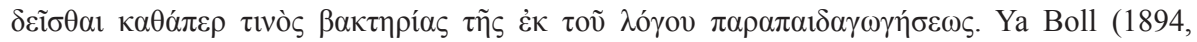
pp. 79-82) señaló las coincidencias entre la doctrina del conocimiento ptolemaica y la de

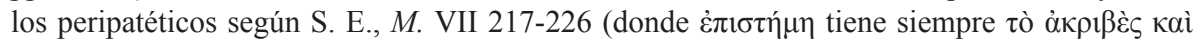

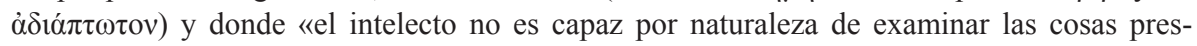
cindiendo de la razón» (ibíd., 226). 


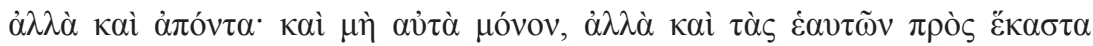

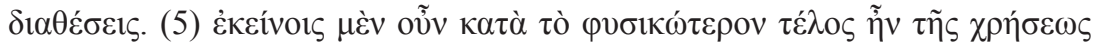

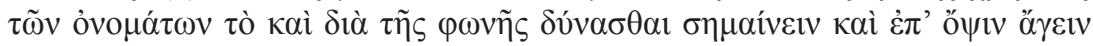

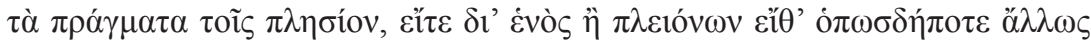

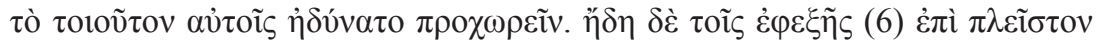

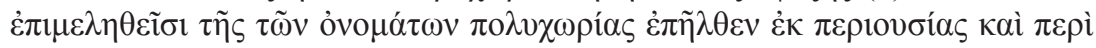

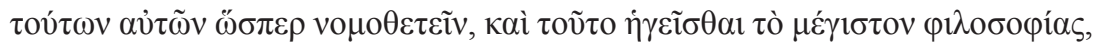

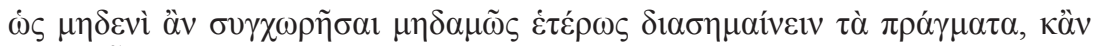

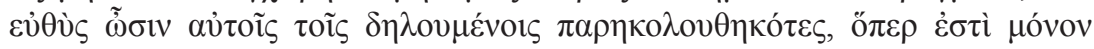

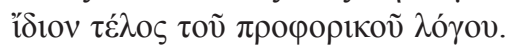

Justo cuando Ptolomeo declara su intención de explicitar cómo funcionan

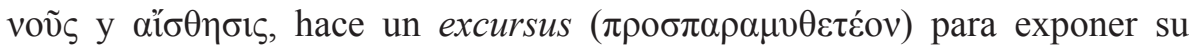
defensa de un lenguaje no técnico, dado que todas las distinciones subsiguientes dependen en última instancia de un lenguaje filosófico.

Ptolomeo comienza estableciendo la utilidad de los términos usuales de cara a la investigación sobre el criterio. La misma discusión se encontraba ya en Aristóteles (Top. 140a3 ss., Rh. 1404b28-30) y más adelante en Galeno (Meth. med. X 70, Diff. puls. VIII 496 K.) ${ }^{44}$ acerca de la terminología médica alejada de la práctica real; según Tolsa ${ }^{45}$ Ptolomeo estaría criticando aquí la que podría ser una de sus fuentes, Aristón de Alejandría (cf. $f r$. 2 Mariotti $=$ Simpl., in Cat. 6 b36 ss., p.188), quien inventó algunos términos al hilo de su comentario a Arist., Cat. 7a4 ss., en el sentido de la necesidad de un lenguaje alejado de tales formas ${ }^{46}$. Quizás no haya que ir tan lejos y recordar que ya Aristóteles había establecido en Top. 140a3 ss. que el uso de términos no habituales es motivo de oscuridad en la definición ${ }^{47}$, e incluso (como Ptolomeo hará después, cf. infra) asocia también la oscuridad a la homonimia. Pero aunque Aristóteles es un texto subyacente a Iudic., este tratado participa más bien de un milieu en el que los científicos de tipo más práctico, como Galeno o el mismo Ptolomeo, abogaban por un uso laxo de los términos técnicos ${ }^{48}$ (como método contra los ataques escépticos), con el añadido de un aporte epicúreo alejado de las sutilezas dialécticas. Como veremos a conti-

\footnotetext{
${ }^{44}$ Como indica Long 1989, p. 174 n.12.

45 Tolsa 2013, p. 142.

${ }^{46}$ Fr. 2.6 Mariotti. Cf. Mariotti 1966, p. 49; Tolsa 2016, p. 470.

${ }^{47}$ Arist., Top. 140a3-5, cf. ibíd., 139b19 ss.

${ }^{48}$ Long 1989, p. 166; cf. Gal., De plac. Hipp. et Plat. IX 7.4 K.
} 
nuación en el origen del lenguaje, el tratamiento epicúreo de éste es bien aceptado por Ptolomeo. Un ejemplo de la posición epicúrea sobre el tema se observa en Erotiano (Vocum Hipp. coll., 34.13-24), y el mismo Epicuro alude a la cuestión en Nat. XXVIII, fr. 12 col. iii Sedley $=31.10$ Arrigh. ${ }^{49}$ :

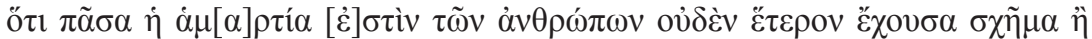

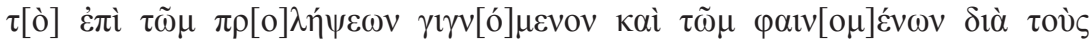

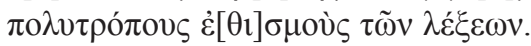

Además de las $\pi \rho 0 \lambda \eta ́ \psi \varepsilon เ \varsigma$, pues, el conocimiento halla trabas en oi

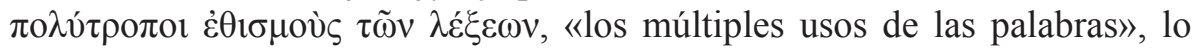
que evoca el período, en la doctrina epicúreo-ptolemaica del origen del len-

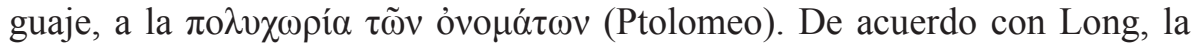
expresión epicúrea implica: a) el uso de un término en más de un sentido (es decir, homonimia), y b) el uso de términos generales, con múltiple referencia (polisemia). Siguiendo la interpretación de Long, la conexión directa entre

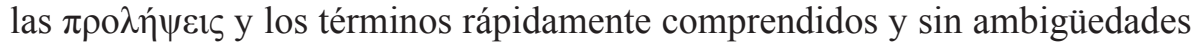
implica un uso legítimo de tales términos ${ }^{50}$. Aquí sin duda encontramos la base para la posterior alusión ptolemaica (infra, 6.1) a los fenómenos de ambiüedad lingüística.

¿Qué entiende Ptolomeo por términos habituales? En 4.2 serían las «palabras usadas por la mayoría $\rangle^{51}$. Más allá de la influencia epicúrea, la defensa de un lenguaje habitual conecta con el momento «natural» en la génesis del lenguaje, y arroja una luz negativa sobre la excesiva creación de palabras en la segunda fase de tal génesis. Rebasa además al epicureísmo en el sentido de que no se trata de кعvoì $\lambda$ óyol (D. L. X 37-38: términos lo suficientemente amplios como para ser ambiguos), sino de términos con amplio peso en la filosofía. Por otra parte, los términos naturales aseguran no sólo no tener que «legislar» sobre ellos, sino también la relación «icónica» entre juicio y expresión. Por tanto, es evidente que este deseo de un lenguaje no técnico no parece seguirse ni en Iudic. ni en Harm.: ambas (como otras de nuestro autor) incorporan muchísimo léxico técnico filosófico de escuelas diversas, sobre

${ }^{49}$ Cf. Long 1971, pp. 123, 128.

${ }^{50}$ Long 1971, p. 125.

${ }^{51}$ Toĩ $\pi \lambda \varepsilon i ́ \sigma \tau o 1 \varsigma ~ \kappa \alpha \theta \omega \mu \imath \lambda \eta \mu \varepsilon ́ v \alpha \varsigma$. Aristóteles, en el pasaje citado de Tópicos, había ejemplificado con términos poéticos de Platón el cómico. Filosóficamente, Dexipo (in Cat. 6.10 ss.) reconoce la necesidad de optar por un léxico conocido o uno abstruso. 
todo estoica, sin pretensión de exactitud ${ }^{52}$; en 5.4 Ptolomeo defiende sólo la utilidad de la terminología. Un somero repaso a la empleada en Iudic. indica

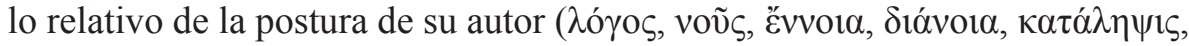

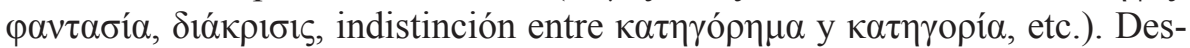
de luego éstas no son «palabras vacías» y quizás no son «las más fáciles de seguir para la mayoría», como se postula infra en 6.2; pero su uso indeterminado conlleva el riesgo de polisemia que explícitamente Ptolomeo quiere superar en 6.1. En otras palabras, se trata de un léxico técnico que se vuelve «habitual» cuando es compartido por todas las escuelas filosóficas post-helenísticas y se vuelve ambiguo. La originalidad de la metáfora judicial en el juicio filosófico probablemente limitaría su ambigüedad a juicio de Ptolomeo.

En cuanto al origen del lenguaje, Long 1989 y Verlinsky 2013 han señalado que la presentación ptolemaica sigue de cerca la de Epicuro (Ep. Herod. $=$ D. L. X 75-76) en lo que es claramente un compromiso entre convención y naturalismo ${ }^{53}$. De acuerdo con Luhtala ${ }^{54}$ la introducción por Aristóteles en De interpretatione del término $\sigma 0 ́ \mu \beta 0 \lambda o v$ cancela la teoría de la imitación (naturalismo) del Crátilo platónico, y si esto es correcto Ptolomeo no estaría siendo muy congruente ahora con la sección anterior donde sí aceptó que $\sigma u ́ \mu \beta o \lambda \alpha$ era lo equivalente a $\delta i \alpha ́ \lambda \varepsilon \kappa \tau o \varsigma$, y que correspondía a $\tau \alpha \grave{~} \delta \iota \alpha v \eta \eta \theta \dot{\varepsilon} v \tau \alpha$ (es decir, una perspectiva no naturalista). Epicuro

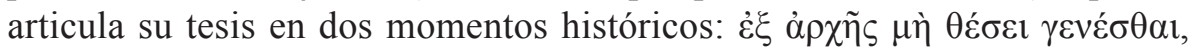

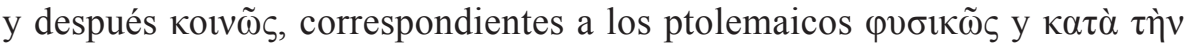

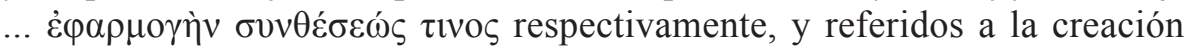

${ }^{52}$ Como afirma Long (1989, p. 155, cf. Tolsa 2016, p. 472), desde época helenística hay un uso indiscriminado de terminología técnica en filosofía que no obliga a una adscripción rigurosa de escuela. Aun así la terminología filosófica de Iudic. no es coincidente plenamente con la de Harm.; para sus relaciones, cf. Feke 2012, pp. 590-593.

${ }^{53}$ En el texto ptolemaico, $\varphi v \sigma ı \kappa \tilde{c} \varsigma$ asegura la visión «naturalista» del origen del lenguaje,

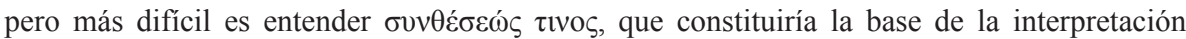
convencionalista. El apoyo es la relación etimológica de $\sigma u ́ v \theta \varepsilon \sigma ı \varsigma$ con la expresión aristotélica

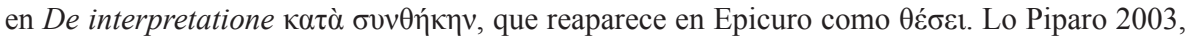
p. 74 ss. expone los problemas asociados a la fórmula aristotélica, y señala que la lectura convencionalista de Aristóteles es más antigua que Amonio, mientras que recuerda que Her-

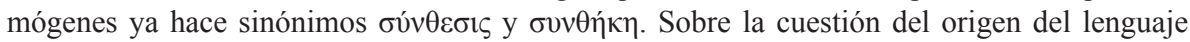
en otros autores cf. Verlinsky 2016.

${ }^{54}$ Luhtala 2011, p. 482. De todas maneras esta autora rebaja la idea de que Aristóteles fuese un absoluto convencionalista. 
individual ${ }^{55}$ seguida de la social. Ptolomeo acepta, como los epicúreos, el origen colectivo del lenguaje una vez formada la sociedad (Lucr. V 1015 ss., sobre todo 1041 ss.), que deriva, como también en el caso de Epicuro (X 76), hacia la variedad lingüística basada en la diversidad humana (Iudic.

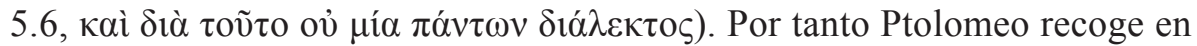
4.3 la doble naturaleza (convencional y natural) del lenguaje de Epicuro ${ }^{56}$. Ahora bien, ¿por qué acepta la doctrina epicúrea? Ptolomeo estaba comprometido con la doble naturaleza del lenguaje dado su rechazo filosófico a la dialéctica (tal y como era entendida por los estoicos) y su opción por un lenguaje natural y fluido como se verá en 6.1-2. Por otro lado, la teoría de Epicuro está destinada a explicar que la fase convencionalista del lenguaje evita ambigüedades y redundancias ${ }^{57}$.

Por último en esta sección presenta (4.6) las consecuencias de la abundancia léxica, lo que en el bosquejo sobre el origen del lenguaje lleva a

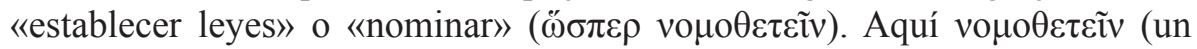

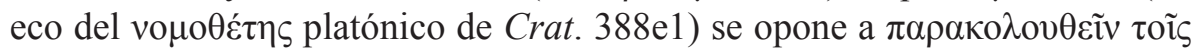

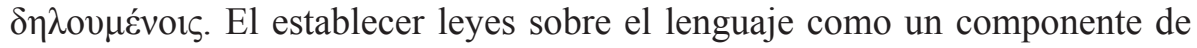
la filosofía hace referencia muy probablemente a la dialéctica estoica (cf. D. L., VII 46-48 = SVF II 130) a la que alude aquí irónicamente Ptolomeo

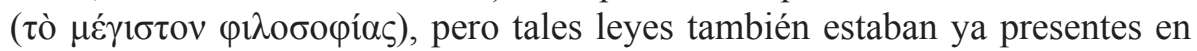
la doctrina aristotélica. La actitud opuesta es, por supuesto, la de los epicúreos (cf. D. L. X 31 y Cic., Fin. I 22).

\section{Las disputas de palabras: Iudic. 5.3-6 (9.1-11 Lamm.)}

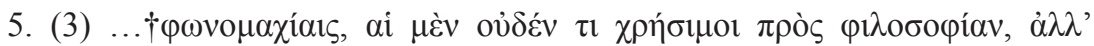

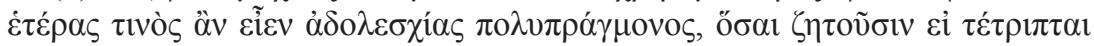

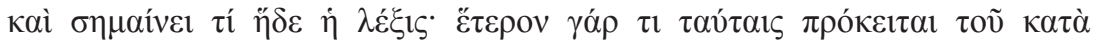

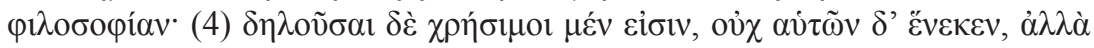

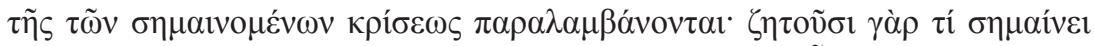

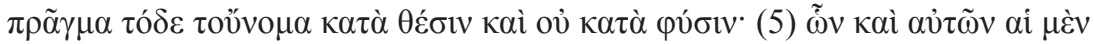

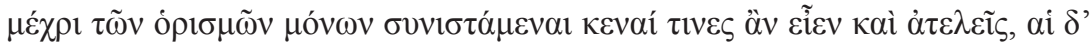

${ }^{55}$ Si bien por individual no hay que entender, en el marco epicúreo, la idea de un «primus inuentior» como demuestra Lucr. X 1041 ss.; cf. además Long 1971, pp. 122, 123.

${ }^{56}$ Cf. D. L. X 76. Proclo (in Cra. 17.6 ss. Pasq. [= test. 335 Us.]) transmite una visión naturalista de Epicuro en la lengua.

${ }^{57}$ Cf. además Verlinsky 2005, p.75. 


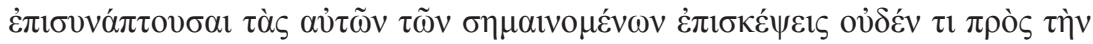

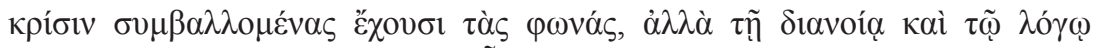

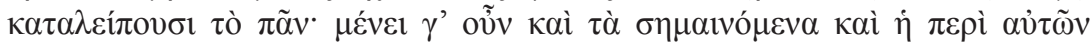

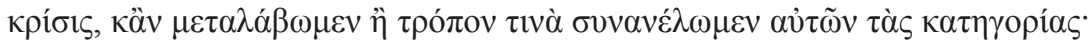

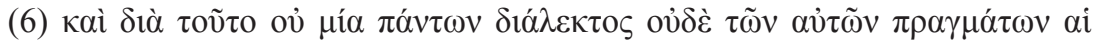

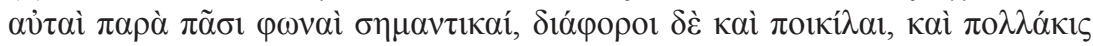

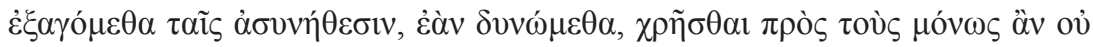

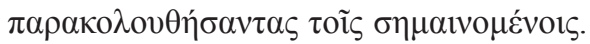

Ptolomeo se ocupa a continuación del valor de las palabras y su uso en filosofía. Antes, en 5.3-4, ha destacado -como preparación- el valor del silencio, reduciendo drásticamente el papel del lenguaje hablado frente al $\lambda$ ó $\gamma$ o

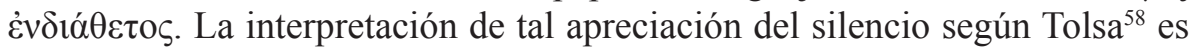
que, si el lenguaje no es convencional porque de algún modo refleja la estructura de la realidad, éste ayuda a transmitir el resultado de la investigación pero no lo investigado en sí mismo ${ }^{59}$. De cualquier forma esto se compadece con la renuencia ptolemaica a $v 0 \mu 0 \theta \varepsilon \tau \varepsilon \tilde{v} v$ y a la indiferencia terminológica que se desprende de 5.6. De nuevo Ptolomeo se apoya en una tradición que fluye desde los pitagóricos y Platón hasta Filón de Alejandría ${ }^{60}$.

El núcleo del pasaje que nos ocupa es el problema en el uso de las palabras. Vuelve veladamente a la discusión presentada supra en cap. 4 acerca de la poca importancia de la terminología técnica, algo que aceptaba con Galeno y que Tolsa 2016 reconduce a una fuente posible de Ptolomeo, Aristón; Long 1989 y también Tolsa 2016 ven una velada influencia de Antíoco de Asca-

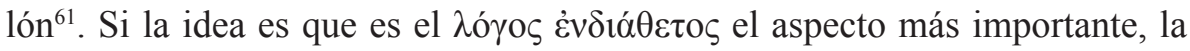
charla sobre el significado de los términos es irrelevante. También aquí nos encontramos el subtexto de Epicuro (Ep. Herod. = D. L. X 38) cuando privilegia que «en cada vocablo atendamos a su sentido primero y que no requie-

58 Tolsa 2013, p. 145.

${ }_{59}$ Parece incongruente el hecho de que el lenguaje no transmita, siquiera en sus términos más primitivos, el objeto de su investigación. Recuérdese no obstante que Ptolomeo habla

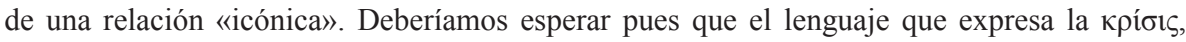
si está de algún modo conectado naturalmente con lo que expresa, sea un reflejo aceptable de las cosas.

${ }^{60}$ Cf. D. L. VIII 10 (= FGrH 566 F 13), Iambl., VP 72; Pl., Sph. 263e, Ti. 37b; Ph., Vit. Mos. I 49.

${ }^{61}$ Antíoco habría mantenido que las diferencias entre escuelas dependen más de la terminología que del fondo de la doctrina: cf. Cic., ND I 16. 
ra explicación, si es que hemos de tener un término al que referir lo que se investiga, se discute o es objeto de opinión». El pasaje ptolemaico, con todo, es difícil de interpretar, y además a juicio de Boll es lacunoso. La oposición

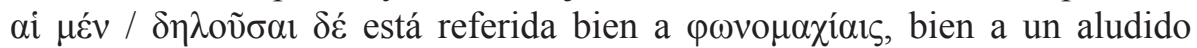
$\lambda \varepsilon \dot{\xi} \xi 1$ s. Si lo entendemos bien, habría: a) palabras o discusiones sobre las palabras, inútiles para la filosofía, en las que se investiga sobre su uso extendido o no, así como si tienen significado. Es posible que en este punto Pto-

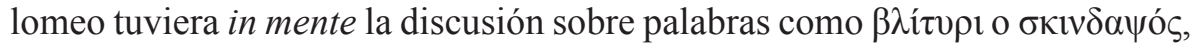
manejadas por los comentaristas de Aristóteles como ejemplos de reunión silábica sin referente ${ }^{62}$ (lo que tiene sentido si se piensa en la alusión posterior

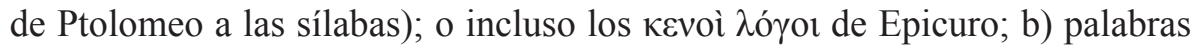
o discusiones propias de la filosofía: esto se daría cuando las palabras sí significan (o tienen un referente: $\delta \eta \lambda$ oṽ $\sigma \alpha \mathrm{l}$ ), y su uso es entonces requerido para la $\kappa \rho i ́ \sigma ı \varsigma^{63}$. En este caso el significado es investigado por su convencionalidad (aunque el lenguaje tenga, como se explicitó en 4.5, una parte originaria de creación naturalista). Éste es el marco de la aceptación de los «términos acostumbrados». Pero ahora pueden ocurrir dos cosas: b.1) llegar a las definiciones (ópıouoí) con un resultado vacuo, o b.2) centrarse en el signifi-

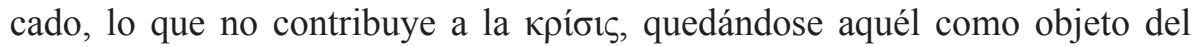

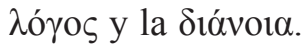

El ataque a la pura «definición» (ópıojós) vuelve a llevarnos tanto a Aristóteles como a la doctrina epicúrea. Ya se ha señalado cómo Aristóteles, en Tópicos, establecía como causa de oscuridad en la definición tanto la homonimia como el uso de términos no habituales. Por su parte, en el texto citado de Cicerón (Fin. I 22) ${ }^{64}$ se hace referencia a Epicuro por «abolir las definiciones», y no enseñar «nada acerca de las divisiones y particiones». De acuerdo con Aristóteles (Ph. 184a23-184b14) una definición «divide» en sus

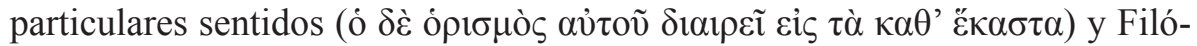
pono (in Ph. 20.10-19) afirmará que una definición analiza lo significado por 1994.

${ }^{62}$ Cf. Chriti 2011, pp. 504, 505; Tolsa 2013, p. 144; sobre los términos, cf. Kotzia-Panteli

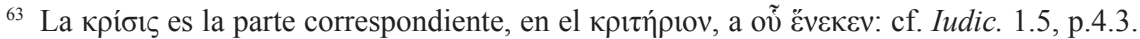

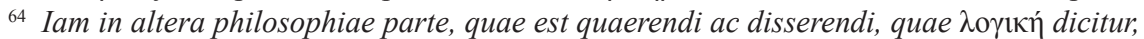
iste uester plane, ut mihi quidem uidetur, inermis ac nudus est. tollit definitiones, nihil de diuidendo ac partiendo docet, non quo modo efficiatur concludaturque ratio tradit, non qua uia captiosa soluantur ambigua distinguantur ostendit; iudicia rerum in sensibus ponit, quibus si semel aliquid falsi pro uero probatum sit, sublatum esse omne iudicium veri et falsi putat. 
el nombre ${ }^{65}$. De acuerdo con Ptolomeo (5.5), las $\varphi \omega v o \mu \alpha \chi \chi^{\prime} \alpha r^{66}$ que llegan tan sólo hasta las definiciones, son vacías y no dan en el blanco, de modo que lo esencial es lo que se quiere significar y no con qué términos se hace ${ }^{67}$.

En lo que respecta al significado, para Ptolomeo, que sigue a Epicuro (cf. D. L. X 38$)^{68}$, la discusión sobre aquél no aporta nada al juicio siendo objeto de pensamiento y razón. Como Ptolomeo explicita (cap. 3), el $\lambda$ óyos es el

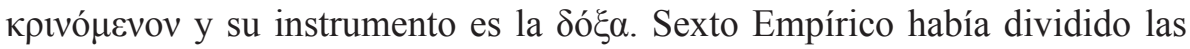
escuelas filosóficas por sus criterios en torno a la verdad (M. VIII 11-13): mientras que los estoicos sí incorporan a su investigación la verdad, los epicúreos se atienen al significante y al objeto, y según Sexto fían lo verdadero

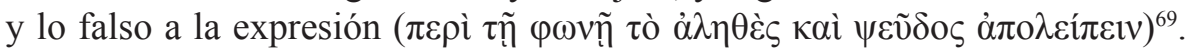
Esta opción forma parte, con matices, de la posición de Ptolomeo sobre la cuestión.

\section{Polisemia, homonimia, sílabas: Iudic. 6.1-2 (10.1-20 Lamm.)}

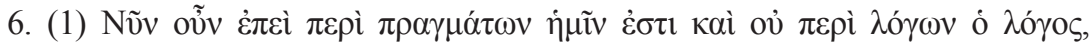

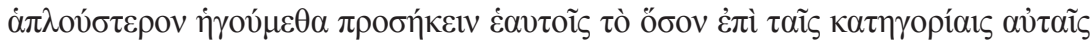

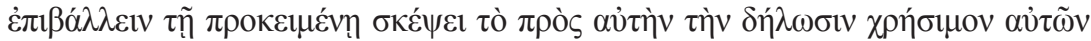

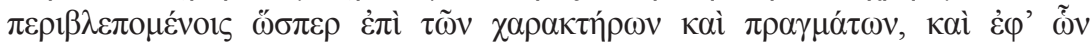

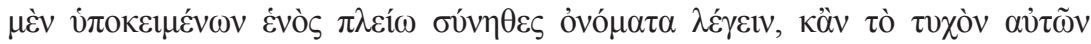

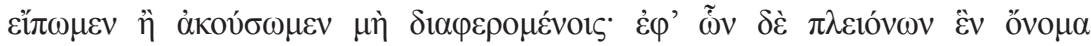

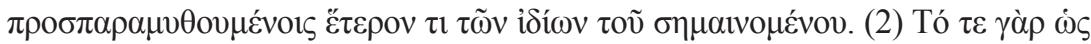

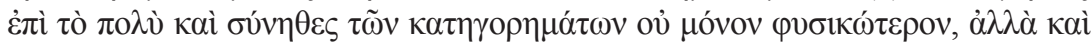

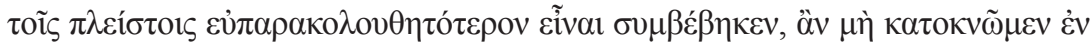

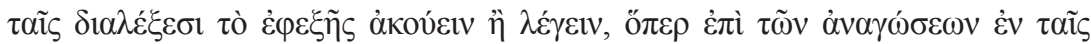

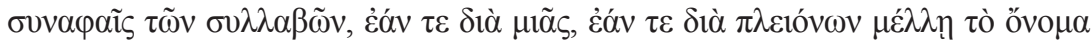

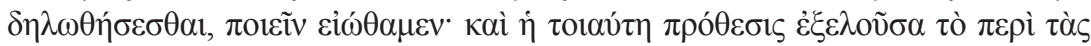

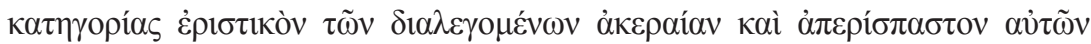

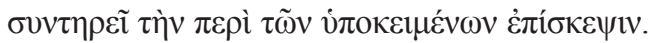

${ }^{65}$ Chriti 2011, p. 506.

${ }^{66}$ Un raro término que sólo parece ser usado (en su correspondiente forma verbal) por Sexto Empírico, H. II 195; cf. Arist., SE 182b23.

${ }^{67}$ Cf. infra cap. 6, una defensa de los términos comunes y la «palabra para la cosa» más bien que «palabras para las palabras», de acuerdo con Epicuro (D. L. X 37, «las cosas que

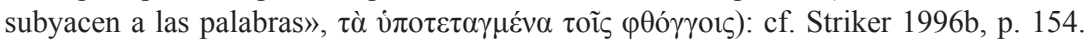

${ }^{68}$ Cf. además Plu., Contra Colotes 1119F.

${ }^{69}$ Cf. Striker 1996b, p. 152 ss. 
Ptolomeo vuelve a evitar la vana discusión sobre terminología y persigue sólo la clarificación. Se trata aquí de otro tópico tanto filosófico como gramatical: la ambigüedad del lenguaje. Por ejemplo, los tipos de $\alpha \mu \varphi \imath \beta o \lambda i ́ \alpha$ están bien estudiados por los estoicos (véase D. L. VII 62 y 193), y Galeno, en De captionibus (XIV 582-598 K.) se hace eco de ellas en su preocupación por el significado (única virtud del lenguaje frente a otras supuestas como la musicalidad o la caligrafía); pero la ventaja de la claridad terminológica ya era defendida desde Aristóteles ( $R h .1404$ b5 y sobre todo en Cat. 1a y Top. 139b, 140a), y Epicuro escribió un $\Pi \varepsilon \rho i ~ \alpha ́ \mu \varphi \imath \beta o \lambda i \alpha \varsigma^{70}$. Como era inevitable, Ptolomeo es consciente de los problemas de la homonimia y de la polisemia, a los que no concede un carácter irresoluble: basta con añadir los matices

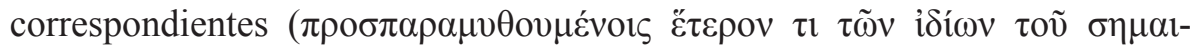

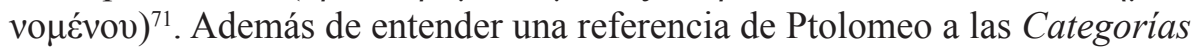
aristotélicas como hace Tolsa ${ }^{72}$, podemos suponer también subyaciendo Tópicos, donde a la oscuridad de la homonimia sigue la del léxico no habitual. Más bien nos encontramos por un lado ante una postura frente a la exactitud demostrada por los estoicos en su recuento de las $\alpha \mu \varphi \imath \beta o \lambda i ́ \alpha 1$ (de hecho, en el esquema del origen-evolución del lenguaje esbozado supra en 4.3-6, en la segunda etapa Ptolomeo había establecido que erróneamente los hombres «dispusieran leyes» ante la abundancia léxica, incluso más allá de las nece-

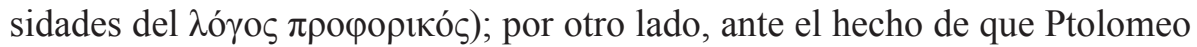
sigue aún en la senda epicúrea de despreocupación por la resolución de los sofismas o ambigüedades, tal y como Cicerón señala (Fin. I 22). No obstante, ello no hace más clara la cuestión de la relación entre las palabras y las cosas. El mismo Epicuro (D. L. X 37-38) privilegiaba, es cierto, «lo que subyace a las palabras» para, acto seguido, referirse al «primer pensamiento (suscitado) por cada palabra», sin necesidad, añade, de «añadir más pruebas». La inmediatez de la primera idea - o si se quiere, acepción- del término evitaría no llegar a una investigación interminable, pues suprime la discusión terminológica ${ }^{73}$.

70 Epicur, Nat. XXVIII, fr. 13, col. V inf. 2 Sedley; cf. Long 1971, p. 123.

${ }^{71}$ Según Huby y Neal 1989, p. 224, Ptolomeo emplea un término utilizado por la Academia nueva en su sentido técnico, $\alpha ં \varepsilon p i ́ \sigma \pi \alpha \sigma \tau o \varsigma$ (cf. S. E., M. VII 166) para caracterizar la supresión de las disputas terminológicas.

72 Tolsa 2013, p. 147, 2016, p. 473.

${ }^{73}$ Cf. Cic., ND I 43, anteceptam animo rei quandam informationem; Striker 1996b, p. 154. El concepto clave para la aprehensión directa de las cosas, según Epicuro, es la $\pi \rho o ́ \lambda \eta \psi 1 \varsigma$ 
En este marco se hace una nueva llamada al uso de los términos usuales (6.2): de esta manera tendríamos el $\lambda$ ó $o \varsigma$ para las cosas y no para el $\lambda$ ó $\gamma \circ \varsigma(6.1)^{74}$. Ello

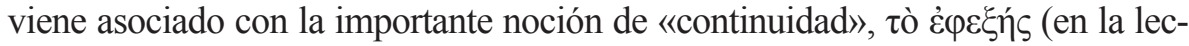
tura, pero sobre todo en la intelección). Esta continuidad, que elimina las disputas

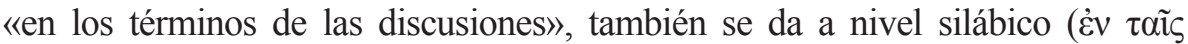

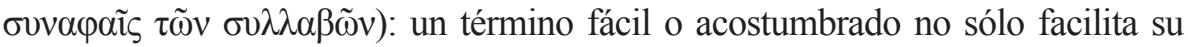
lectura o emisión, sino que además se integra fácilmente en el discurso, evitando las $\varphi \omega v o \mu \alpha \chi i ́ a r$ (producto de la necesidad de un silabeo lento, lo contrario de $\tau$ ò $\dot{\varepsilon} \varphi \varepsilon \xi \tilde{\eta} \varsigma)$ y, de paso, eliminando la necesidad de las definiciones. Tal estrecha relación entre significado, definición y silabación se leerá también en Filópono, in Ph. 20.10-19. Ptolomeo sigue el modelo epicúreo mostrado por Cicerón (Fin. I 22) y va contra la insistencia estoica en la definición (cf. D. L. VII 60-62), pero también aboga por evitar un juicio erróneo derivado de un lenguaje no natural. Tolsa ${ }^{75}$ considera esta referencia a las sílabas como una crítica velada a las Cate-

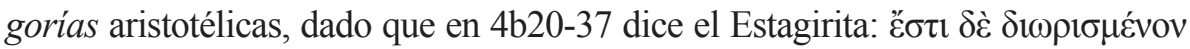

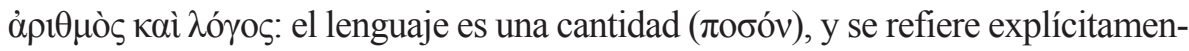

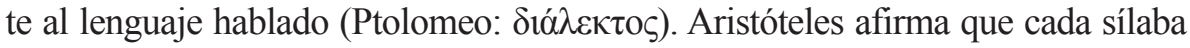
está separada en sí misma ${ }^{76}$; los comentaristas de Aristóteles se centran en el hecho de que el ensamblaje silábico de una palabra no adquiere su coherencia por el significado de la palabra, pues términos como $\beta \lambda i ́$ tupt (carentes de significado) pueden ser descompuestos en sílabas ${ }^{77}$. En tal discusión no entra Ptolomeo, pero esta perspectiva es equivalente a su rechazo de la definición en tanto que análisis. Se puede observar esquemáticamente las oposiciones establecidas:

\begin{tabular}{|c|c|}
\hline Uso de términos usuales & Uso de términos inusuales \\
\hline Continuidad ( $\tau$ ò $\dot{\varepsilon} \varphi \varepsilon \xi \tilde{\eta} \varsigma$ ) & No continuidad ( $=$ cantidad, $\tau$ ò $\pi$ oбóv) \\
\hline Silabeo fluido & Silabeo discontinuo \\
\hline$\lambda o ́ \gamma o \varsigma \pi \varepsilon \rho \grave{~} \pi \rho \alpha \gamma \mu \alpha ́ \tau \omega \nu$ & 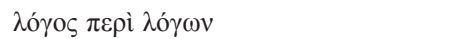 \\
\hline
\end{tabular}

(término no empleado por Ptolomeo): en D. L. X 33 leemos que la conexión entre la pronunciación de un término y su representación mental es directa (cf. Long 1971, p. 120).

${ }^{74}$ Una expresión eco de la que recoge Diógenes Laercio sobre Epicuro en X 31,

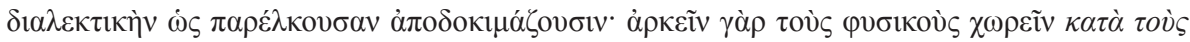
$\tau \tilde{\omega} v \pi \rho \alpha \gamma \mu \alpha \dot{\tau} \tau \omega v \varphi \theta \dot{\gamma} \gamma \gamma o v \varsigma$.

75 Tolsa 2013, p. 143.

${ }^{76}$ Cf. Ackrill 1963, p. 92; Chriti 2011, p. 503.

${ }_{77}$ Cf. Porph., in Cat. 102.2-9, y Chriti 2011, pp. 505, 506 para otros pasajes. 


\section{Conclusión. El lenguaje como herramienta}

Ptolomeo concluye su excursus sobre el lenguaje (6.3) aludiendo a su carácter meramente instrumental, y pasa a la consideración de los «elementos del criterio», percepción y pensamiento:

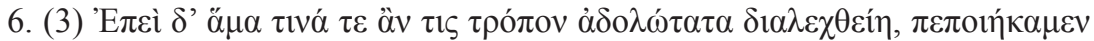

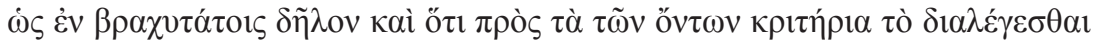

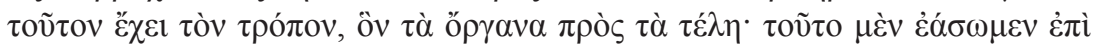

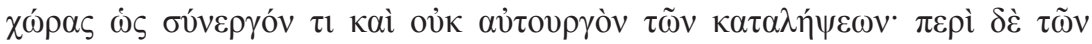

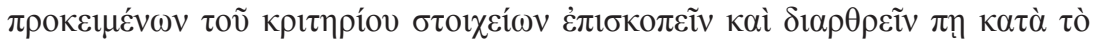

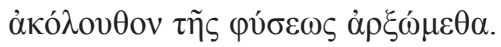

Así, el lenguaje no es un instrumento con el que se agota el tratamiento de las $\kappa \alpha \tau \alpha \lambda \eta ́ \psi \varepsilon ı \varsigma$ (un término técnico de la epistemología estoica, por lo demas tratado libremente por Ptolomeo $)^{78}$. Por ejemplo, en la subsiguiente sección sobre la distinción entre cuerpo y alma, explícitamente se recuerda que no estamos ante una discusión terminológica sino ante las diferencias reales. De este modo, el lenguaje no es una herramienta inextricablemente unida al pensamiento, sino un mero auxiliar externo: un auxiliar que no debe generar problemas de entendimiento a través de ambigüedades o sutilezas terminológicas, sino señalar los objetos mismos. En esto Ptolomeo tampoco es original, pues la discusión sobre el lenguaje en su época se preocupa por evitar y controlar las $\alpha \mu \varphi \imath \beta o \lambda i ́ \alpha$; y como científico práctico que era, comparte con un Galeno una concepción utilitarista del lenguaje, y no como un fin en sí mismo.

En suma, la perspectiva ptolemaica sobre el criterio de conocimiento es básicamente práctica, relativamente cercana a los comentarios a Aristóteles y con la articulación de un material disperso libre de la exactitud terminológica ${ }^{79}$. Pero más allá de esta opción utilitarista (presente además en otras obras de su corpus como Harmonica), Ptolomeo privilegia, en lo que al lenguaje respecta, la facultad de razonamiento interno sobre la facultad expresiva (que él establece como reflejo de aquél). Como consecuencia, elude los problemas técnicos propios de la dialéctica estoica de su tiempo (consi-

${ }^{78}$ Cf. Long 1989, p. 176 n.36; Tolsa 2016, p. 472. La idea del lenguaje como instrumento aparece ya en Pl., Cra. 388e.

${ }^{79}$ Cf. Tolsa 2016, p. 475, que insiste en la influencia de Antíoco de Ascalón en Iudic. 
dérese que los estoicos asignan la verdad o falsedad a las proposiciones, no directamente a los hechos: cf. S. E., M. VIII 11$)^{80}$. Aquí reside su originalidad: centrándose en los objetos mismos, a los que va dirigida la кpíбıs, acepta el valor de los significantes lingüísticos sólo si no provocan ambigüedades al no tratarse de términos usuales; pero mientras que para Epicuro ambos extremos (significante y referente) están al mismo nivel ${ }^{81}$, para Ptolomeo el papel del lenguaje es auxiliar y la verdad puede alcanzarse en silencio. Por último, respecto a la doctrina estoica Ptolomeo no acepta los $\lambda \varepsilon \kappa \tau$ ó: éstos son caracterizados en todas las fuentes como incorpóreos, y Ptolomeo se apoya en un pragmatismo de corte epicúreo en el que el análisis lingüístico no tiene cabida (de acuerdo con 7.2, uno puede observar la diferencia entre dos cosas aunque su terminología se cambie «mil veces»). El informe de Sexto Empírico ( $M$. VIII 12) iguala la cosa significada con el enunciado: la verdad o falsedad se traslada al enunciado, con lo que, según Ptolomeo, se llega a las «definiciones» y a cuestiones de $\lambda$ ó ${ }^{\circ} \varsigma$ y $\delta$ tóvola, pero no de кpíбıs. El mismo Sexto alude a la opción de Epicuro, la de confiar tan sólo en la expresión $(\tau \tilde{n} \varphi \omega v \tilde{n})^{82}$. Pero según él habría otra posibilidad (que considera «mera invención de escuela»), la de quienes sitúan lo verdadero «en la actividad del pensamiento». Es en esta opción inverosímil para Sexto donde debemos probablemente situar a Ptolomeo.

\section{BIBLIOGRAFÍA}

Ackrill, J. L. 1963: Aristotle. Categories and De Interpretatione, Oxford.

Arbo, Ag. y Al. 2006: «Les animaux sont-ils musiciens? Autour d'un theme de la réflexion musicale antique», en Mortier-Waldschmidt, O. (ed.), Musique \& Antiquité. Actes du colloque d'Amiens, París, pp. 209-243.

80 Para Ptolomeo (Iudic. 11.1) tanto razón como percepción dicen la verdad aunque los «primeros criterios» (12.1) puedan dar lugar a equívocos. Para Epicuro todo lo sensible es verdadero y no hay diferencia entre afirmar la verdad de algo y su existencia (y la percepción capta completamente la verdad: S. E., M. VIII 9-10).

81 Cauchy 1986, pp. 330 ss. Pero cf. Long 1971, p. 121 señalando que las $\pi \rho 0 \lambda \eta ́ \psi \varepsilon 1 \varsigma$, tal y como son descritas en D. L. X 33, son mediaciones análogas a los $\lambda \varepsilon \kappa \tau$ ó estoicos entre la cosa y su significante.

82 El término epicúreo tiene pues una restricción filosófica importante frente a los «enunciados» estoicos, que entran en el juego de la lógica. 


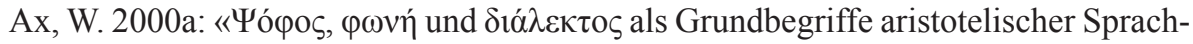
reflexion», en Ax, W. (ed.), Lexis und Logos. Studien zur antiken Grammatik und Rhetorik, Stuttgart, pp. 19-39 [= Glotta 56, 1978, pp. 245-271].

Ax, W. 2000b: «Der Einfluß des Peripatos auf die Sprachtheorie der Stoa», en Ax, W. (ed.),, Lexis und Logos. Studien zur antiken Grammatik und Rhetorik, Stuttgart, pp. 73-94 [= Döring, K. y Ebert, Th. (eds.), Dialektiker und Stoiker, Stuttgart 1993, pp. 11-32].

Bobo de la Peña, M. 2009: «Ptolemy on Sound: Harmonics 1.3 (6.14-9.15 Düring)», Mnemosyne 62, pp. 548-585.

Boll, F. 1894: Studien über Claudius Ptolemäus. Ein Beitrag zur Geschichte der griechischen Philosophie und Astrologie, Leipzig.

Cauchy, V. 1986: «Critique de la théorie du signe et langage chez Sextus Empiricus», en Philosophie du Langage et Grammaire dans l'Antiquité, Actes du colloque international, Grenoble, 3 - 6 septembre 1985, Bruselas - Grenoble, vol. II, pp. 325-338.

Chiesa, C. 1986: «Symbole et signe dans le De Interpretatione», en Philosophie du Langage et Grammaire dans l'Antiquité, Actes du colloque international, Grenoble, 3 - 6 septembre 1985, Bruselas - Grenoble, vol. I, pp. 203-218.

Chiesa, C. 1993: «Le problème du langage intérieur dans la philosophie antique de Platon à Porphyre», Histoire Épistemologie Langage 14(2), pp. 15-30.

Chriti, M. 2011: «Neoplatonic Commentators on Aristotle: The 'Arbitrariness of the Linguistic Sign'», en Marinatos, S., Montanari, F. y Rengakos, A. (eds.), Ancient Scholarship and Grammar. Archetypes, Concepts and Contexts, Berlín - Nueva York, pp. 499-514.

Düring, I. 1934: Ptolemaios und Porphyrios über die Musik, Göteborg.

Feke, J. 2012: «Mathematizing the soul: The development of Ptolemy's psychological theory from On the Kritêrion and Hêgemonikon to the Harmonics», SHPS 43, pp. 585-594.

Frede, E. 1978: «Principles of Stoic Grammar» en Reist, J. M. (ed.), The Stoics, Berkeley, Los Ángeles - Londres, pp. 27-76.

Huby, P. y Neal, G. (eds.) 1989: The Criterion of Truth. Essays written in honour of George Kerferd together with a text and translation (with annotations) of Ptolemy's On the Kriterion and Hegemonikon, Liverpool, pp. 182-214.

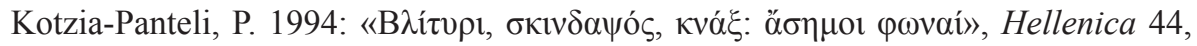
pp. 7-29.

Lammert, F. 1917: «Ptolemaios Perì kritēríou kaì hēgemonikô̂ und die Stoa», WS 39, pp. 249-258.

Lammert, F. 1961: Claudii Ptolemaei opera quae exstant omnia, vol. III 2, Leipzig.

Lo Piparo, F. 2003: Aristotele e il linguaggio. Cosa fa di una lingua una lingua, Roma - Bari. 
Long, A. A. 1971: «Aisthesis, Prolepsis and Linguistic Theory in Epicurus», BICS 18, pp. 114-133.

Long, A. A. 1989: «Ptolemy on the Criterion: an Epistemology for the Practising Scientist», en Huby, P. y Neal, G. (eds.), The Criterion of Truth. Essays written in honour of George Kerferd together with a text and translation (with annotations) of Ptolemy's On the Kriterion and Hegemonikon, Liverpool, pp. 151-178.

Lucci, G. 1980: "Criterio e Metodologia en Sesto Empirico e Tolomeo», Annali dell'Istituto di Filosofia di Firenze 2, pp. 23-52.

Luhtala, A. 2011: «Imposition of Names in Ancient Grammar and Philosophy», en Marinatos, S., Montanari, F. y Rengakos, A. (eds.), Ancient Scholarship and Grammar. Archetypes, Concepts and Contexts, Berlín - Nueva York, pp. 479-498.

Mansfeld, J. 2005: «'Illuminating What Is Thought'. A Middle Platonist placitum on 'Voice' in Context», Mnemosyne 58, pp. 358-407.

Manuli, P. 1981: «Claudio Tolomeo: il criterio e il principio», RSF 36, pp. 64-88.

Mariotti, I. 1966: Aristone d'Alessandria. Edizione e interpretazione, Bolonia.

Schenkeveld, D. M. 1990: "Studies in the History of Ancient Linguistics, III: the

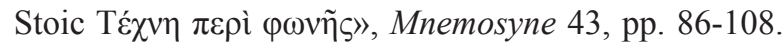

Schiefsky, M. J. 2014: «The Epistemology of Ptolemy's On the Criterion», en MiKyoung Lee (ed.), Strategies of Argument. Essays in Ancient Ethics, Epistemology and Logic, Oxford, pp. 301-331.

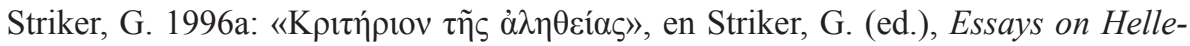
nistic Epistemology and Ethics, Cambridge, pp. 22-76.

Striker, G. 1996b: «The problem of the criterion», en Striker, G., Essays on Hellenistic Epistemology and Ethics, Cambridge, pp. 150-165.

Tarrant, H. 1985: Scepticism or Platonism? The Philosophy of the Fourth Academy, Cambridge.

Tolsa, C. 2013: Claudius Ptolemy and Self-Promotion. A Study on Ptolemy's Intellectual Milieu in Roman Alexandria, Ph. Diss., Universitat de Barcelona.

Tolsa, C. 2016: «Ptolemy's law court analogy and Alexandrian philosophy», AncPhil 34, pp. 465-477.

Verlinsky, A. 2005: «Epicurus and his predecessors on the origin of language», en Frede, D. y Inwood, B. (eds.), Language and Learning. Philosophy of language in the Hellenistic Age, Cambridge, pp. 56-100.

Zirin, R. A., 1980: «Aristotle's Biology of Language», TAPhA 110, pp. 325-347.

Fecha de recepción de la primera version del artículo: 26/10/2016

Fecha de aceptación: 05/01/2017

Fecha de recepción de la version definitiva: 17/01/2017 